\title{
Multiple Sclerosis: \\ Associations Between \\ Physical Disability \\ and Depression Are \\ Not Mediated by \\ Self-Reported \\ Physical Activity
}

Perceptual and Motor Skills

$0(0) 1-18$

(C) The Author(s) 2017

Reprints and permissions: sagepub.com/journalsPermissions.nav

DOI: $10.1|77 / 003| 5|25| 77|185|$

journals.sagepub.com/home/pms

@SAGE

Dena Sadeghi Bahmani ', Pasquale Calabrese ${ }^{2}$, Helene Merkt ${ }^{2}$, Yvonne Naegelin ${ }^{3}$,

Markus Gerber ${ }^{4}$, Uwe Pühse ${ }^{4}$,

Edith Holsboer-Trachsler', and Serge Brand ${ }^{1,4}$

\begin{abstract}
This study investigated the interrelatedness of physical disability, physical activity, and depression among patients with multiple sclerosis (MS). We hypothesized that self-reported physical activity would mediate the effect of disability on depressive symptoms. Twenty-seven patients with MS (mean age: 49 years; $44.5 \%$ females) completed self-rating scales covering sociodemographic variables, intake of antidepressants, physical activity, and symptoms of depression; disability was
\end{abstract}

\footnotetext{
'Psychiatric Clinics (UPK), Center for Affective, Stress and Sleep Disorders (ZASS), University of Basel, Basel, Switzerland

${ }^{2}$ Division of Molecular and Cognitive Neurosciences, Faculty of Psychology, University of Basel, Basel, Switzerland

${ }^{3}$ Department of Neurology, University Hospital, Basel, Switzerland

${ }^{4}$ Department of Sport, Exercise and Health, Division of Sport and Psychosocial Health, Faculty of Medicine, University of Basel, Basel, Switzerland
}

Dena Sadeghi Bahmani and Pasquale Calabrese share first authorship.

\section{Corresponding Author:}

Dena Sadeghi Bahmani, Center for Affective, Stress and Sleep Disorders (ZASS), University of Basel, Psychiatric Clinics (UPK), Wilhelm Klein-Strasse 27, 4002 Basel, Switzerland.

Email: Dena.Sadeghibahmani@upkbs.ch 
measured by the Expanded Disability Status Scale. We found a higher level of disability to be significantly associated with more symptoms of depression. While higher reported physical activity was descriptively associated with lower depression scores and unrelated to Expanded Disability Status Scale, physical activity levels did not mediate the effect of disability on depressive symptoms.

\section{Keywords}

disability, physical activity, depressive symptoms, multiple sclerosis, mediation effect

\section{Introduction}

Multiple sclerosis (MS) is an autoimmune, chronic, inflammatory, demyelinating, neurodegenerative disease (Compston \& Coles, 2008; Howard, Trevick, \& Younger, 2016). With its progressive character, MS is one of the most physically disabling nontraumatic neurological diseases in early adulthood (Guimaraes \& Sa, 2012; Howard et al., 2016). Both inflammation and neurodegeneration seem to underlie the pathogenic process of MS (Compston \& Coles, 2008; Howard et al., 2016). Accordingly, inflammation and neurodegeneration are both linked to increasing neurological and physical impairment, which consequently worsen with the course of the disease (Motl, 2010). Depending on the degree and duration of illness progression, MS may impair gait, gross motor, and fine motor skills. Patients might be fully ambulatory, with or without aid, for longer distances, or they might not be able to walk $100 \mathrm{~m}$ without resting. Typical impairments encompass sensory and motor dysfunction of the extremities, visual disturbances, gait impairment, cognitive dysfunction, neuropsychiatric disorders, fatigue (Chiaravalloti \& DeLuca, 2008; Lode et al., 2009; Motl \& Pilutti, 2012; Stuve \& Oksenberg, 1993), and paraesthesia (a sensory dysfunction characterized by sensations such as tingling, tickling, pricking, numbness or burning of the skin; Razazian et al., 2016).

As regards psychological symptoms of MS, patients often report fatigue, paresthesia, and depression. The incidence of depression in patients with MS is $40 \%$ to $50 \%$ higher than in the general population (Dalgas, Stenager, Sloth, \& Stenager, 2015; Ensari, Motl, \& Pilutti, 2014; Feinstein, Magalhaes, Richard, Audet, \& Moore, 2014; Goretti, Portaccio, Zipoli, Razzolini, \& Amato, 2010; Jones et al., 2014; McCabe, McKern, \& McDonald, 2004; Montel, Spitz, \& Bungener, 2012; Patten, Beck, Williams, Barbui, \& Metz, 2003; Patten et al., 2006; Siegert \& Abernethy, 2005). Symptoms of depression have also been associated with multiple psychosocial and health-related factors, including a decreased quality of life (Ensari et al., 2014), impaired cognitive functioning (Ensari et al., 2014), reduced work performance, lower treatment compliance 
(Gold et al., 2011), and increased morbidity and mortality (Feinstein et al., 2014; Gold \& Irwin, 2009). Accordingly, prevention and treatment of depression are crucial to disease management.

Intervention recommendations for depression in MS are based on general population guidelines (Brenner \& Piehl, 2016), as the literature indicates similar patient benefits from pharmacological (Koch, Galzenborg, Uyttenboogaar, Mostert, \& DeKeyser, 2011) and psychological treatments such as cognitive behavioral and interpersonal therapies (Fiest et al., 2016). However, as regards antidepressants, we also note that remission rates in patients with major depressive disorders range between $40 \%$ and $60 \%$, with maximum adherence rates of $50 \%$ after treatment onset (Haghighi et al., 2014). As a result, there is still a need for more research to identify the specific challenges of treating depressive symptoms in general, and in patients with MS.

As an additional strategy for coping with symptoms of depression, regular physical activity has gained increased attention for its efficacy in nonclinical samples (Cooney et al., 2013; Josefsson, Lindwall, \& Archer, 2014; Krogh, Nordentoft, Sterne, \& Lawlor, 2011; Lawlor \& Hopker, 2001; Mead et al., 2009; Rethorst, Wipfli, \& Landers, 2009; Stathopoulou, Powers, Berry, Smits, $\&$ Otto, 2006), among patients with major depressive disorders (Gerber, Holsboer-Trachsler, Puhse, \& Brand, 2016; Hallgren, Vancampfort, \& Stubbs, 2016; Rosenbaum, Tiedemann, Ward, Curtis, \& Sherrington, 2015; Schuch, Morres, Ekkekakis, Rosenbaum, \& Stubbs, 2017; Stubbs, Rosenbaum, Vancampfort, Ward, \& Schuch, 2016), and among patients with MS (Dalgas et al., 2015; Ensari et al., 2014; Razazian et al., 2016). Importantly, patients with MS are less physically active compared with the general population (Giesser, 2015; Latimer-Cheung et al., 2013; McDonnell, Smith, \& Mackintosh, 2011; Motl, Dlugonski, Pilutti, Sandroff, \& McAuley, 2012; Motl \& Pilutti, 2012, 2016; Pilutti, Platta, Motl, \& Latimer-Cheung, 2014; Ploughman et al., 2014; Waschbisch, Tallner, Pfeifer, \& Maurer, 2009), though this difference in activity level is not present at disease onset (Sadeghi Bahmani et al., 2016). Of course, physical inactivity in this population might derive in part from neurological problems with the motor system, and such other MS-related symptoms as visual impairment, incontinence, dysarthria, nystagmus, cognitive impairments, and low sensitivity that contribute to increasing disability (Devine \& Zafonte, 2009; Giesser, 2015; McDonnell et al., 2011; Motl \& Pilutti, 2012; Waschbisch et al., 2009), leading several researchers to attribute physical inactivity to interfering physical disability in this population (Marck et al., 2014b; Motl, 2010; Snook \& Motl, 2008).

An association of higher physical disability and more numerous depressive symptoms has been observed among elderly individuals (Cole \& Dendukuri, 2003; Cronin-Stubbs et al., 2000; Kennedy, Kelman, \& Thomas, 1990; Strawbridge, Deleger, Roberts, \& Kaplan, 2002; Turner \& Noh, 1988) and among patients with MS, though, for patients with MS, results were mixed. 
Researchers have observed an increasing risk of developing depressive symptoms with increasing disability, as measured by the Expanded Disability Status Scale (EDSS; Kurtzke, 1983) among patients with MS generally (Chwastiak et al., 2002; Jones et al., 2014; Kurtzke, 1983; Marck et al., 2014a; Mcivor, Riklan, \& Reznikoff, 1984; Millefiorini et al., 1992; Mohr, Goodkin, Gatto, \& VanDerWende, 1997), and others reported higher depression rates in patients with MS, compared with individuals with a similar disability levels suffering from other diseases (Patten et al., 2003; Rabinowitz \& Arnett, 2009; Siegert \& Abernethy, 2005). In other words, physical disability and symptoms of depression are not necessarily or linearly associated, and the involvement of mediating or moderating factors is likely. Specifically, physical activity might interact with disability and depression to modify this relationship.

This study sought to investigate physical activity level as a mediating factor between disability and depression and to thereby explain prior inconsistencies in research findings. We hoped that increased physical activity might improve the treatment of patients with MS who reported both higher degrees of disability and depression. We formulated two hypotheses and one exploratory research question. First, following others (Chwastiak et al., 2002; Kurtzke, 1983; Mcivor et al., 1984; Millefiorini et al., 1992; Mohr et al., 1997), we expected higher neurologist determined disability scores to be associated with higher selfreported depression scores in our sample of patients with MS. Second, following others (Archer, Josefsson, \& Lindwall, 2014; Josefsson et al., 2014; Schuch, Morres, et al., 2017; Stubbs et al., 2016; Vancampfort et al., 2015), we hypothesized that higher self-reported physical activity levels would be associated with lower symptoms of depression. Our exploratory research question was whether and to what extent physical activity might mediate the relationship between disability and depression.

\section{Method}

\section{Procedures}

Patients with MS within an international cohort study at the University Hospital of Basel (Switzerland) were asked to participate in the present study and in an additional cross-sectional and questionnaire-based study at the same University Hospital. Potential participants were informed about the study's aims, the voluntary basis of participation, and the confidential handling of data. Thereafter, they signed a written informed consent and completed self-rating questionnaires covering sociodemographic data including disease duration, physical activity, and symptoms of depression (see later). Their disability levels were measured by a neurologist, using the EDSS. The local ethics committee approved the study as an amendment to an ongoing cohort study (EKNZ-Nr.: 285/11) performed in accordance with the rules laid down in the Declaration of Helsinki. 
Twenty-seven patients (mean age: $M=49.00$ years, $S D=14.5 ; 12$ [44.5\%] women and $15[55.5 \%]$ men) participated in the study, and their EDSS (see later) scores and disease duration data were extracted from the cohort study data. Inclusion criteria were as follows: (a) physician-determined MS diagnosis (following the diagnostic criteria) irrespective of subtype (relapse-remitting, primary progressive, and secondary progressive); (b) neurologist-rated EDSS score below 5.0; (c) age between 30 and 65 years; (d) willing and able to participate in the study as attested by signed written informed consent; and (e) able to read and write in German. Exclusion criteria were as follows: (a) further neurological and psychiatric disorders; and (b) intake of medications apart from MS-related medications and antidepressants. Twenty-three participants were diagnosed with relapse-remitting MS, two with a primary-progressive course, and two with secondary-progressive MS. The mean disease duration was 15 years $(S D=7.5$; mean EDSS was 3.5).

\section{Measures}

Physical disability. Expanded Disability Status Scale (EDSS) was assessed by trained neurologists. The EDSS is an accepted and widely used tool to objectively assess disability levels of patients with MS. The total score is ranked on a scale from 0 to 10, with increments of 0.5 to 1 (Kurtzke, 1983), and with higher scores reflecting higher levels of disability. Meyer-Moock, Feng, Maeurer, Dippel, and Kohlmann (2014) reported in their systematic review the high validity and reliability of the EDSS. They further conclude that the EDSS is suitable to describe the clinical status and the physical disability and to monitor disease progression.

Physical activity. Patients completed the short form of the German version of the International Physical Activity Questionnaire (IPAQ; Craig et al., 2003). The IPAQ is a self-reported questionnaire based on a 7-day recall inventory, which addresses four domains: Vigorous and moderate activities, time spent walking, and time spent sitting. The days per week, and number of minutes per day, during which the activities are performed, are assessed. Values are truncated, if duration per day exceeds 180 minutes. All domains apply to working and leisure time physical activity (Craig et al., 2003). Craig et al. (2003) reported the following psychometric properties: test-retest reliability: Spearman's Rho: 0.80. Further, the criterion validity had a median (rho) of about 0.30: Following Craig et al. (2003), the latter result was comparable to most other self-report validation studies.

The IPAQ scores can be treated as categorical and continuous data, calculated on the basis of multiples of the resting metabolic rate (MET), which is then multiplied by minutes of activity performed per week. The MET score for vigorous activities is 8 , for moderate activities 4 , and for walking 3.3 (IPAQ Research Committee, 2005). Categorical scores encompass the distinction of 
high, moderate, and low participation and were determined according to the guidelines of the IPAQ Research Committee (2005).

Depression symptoms. To assess symptoms of depression, patients completed the Beck Depression Inventory (BDI; Beck, Ward, Mendelson, Mock, \& Erbaugh, 1961) as part of the cohort study. The BDI was found to be an adequate diagnostic measure for detecting and grading depressive symptoms in various populations including MS patients (Benedict, Fishman, McClellan, Bakshi, \& Weinstock-Guttman, 2003; Sacco et al., 2016). The BDI consists of 21 items and asks about different dimensions such as depressive mood, loss of appetite, sleep disorders, and suicidality. Each question has a set of at least four possible responses, ranging in intensity; for example, "sadness": $0=I$ do not feel $\mathrm{sad} ; 1=I$ feel sad; $2=I$ am sad all the time and I can't snap out of it; $3=I$ am so sad or unhappy that I can't stand it, and with higher scores reflecting greater severity of depressive symptoms. Scores range from 0 to 63; the categorical subdivisions are as follows: 0-13 points none or minimal, 14-19 mild, 20-28 moderate, 29-63 severe depressive symptoms (Kuhner, Burger, Keller, \& Hautzinger, 2007). Therefore, the scores can be treated as continuous and categorical values.

Medication use (antidepressants). Participants were asked to report the intake of antidepressants (ADs; answers: yes vs. no; if yes: brand name, dosage, and possible side effects).

\section{Statistical Analysis}

Analyses were performed with SPPS ${ }^{\circledR}$ Version 23.0 (IBM Corporation, Armonk NY, USA) for Apple $\mathrm{Mac}^{\circledR}$. The mediator analysis was conducted using two different approaches. On one hand, the guidelines established by Baron and Kenny (1986) were applied using multiple regression analyses. On the other hand, the PROCESS syntax by Hayes (2012) was employed to estimate the indirect associations more precisely.

The procedure established by Baron and Kenny (1986) was utilized to investigate the relationships within the variables and to estimate their indirect association. This approach comprises four steps. First, the independent variable "physical disability" should be significantly related to the dependent variable "depressive symptoms." Second, the independent variable "physical disability" should be significantly related to the mediator "physical activity." Third, the mediator "physical activity" should affect the dependent variable "depressive symptoms." Fourth, mediation is likely if the effect of the independent variable "physical disability" on the dependent variable "depressive symptoms" is reduced, compared with the result in step one, by controlling for the mediator "physical activity." 
The PROCESS version 2.15 (Hayes, 2012) was used due to the small sample size in this study to assure the results. According to Hayes (2015), it is a least squares or logistic regression-based path analytic framework for estimating direct and indirect effects in single and multiple mediator models. The bootstrap method is used for the estimation of an indirect effect. This technique has been reported to be superior to other methods in small to moderate samples (Preacher \& Hayes, 2008).

Physical activity was treated as a potential mediator between physical disability and depressive symptoms. The IPAQ total score for physical activity was used, and the covariates age, sex, and disease duration were included in all analyses.

\section{Results}

\section{Participant Descriptive Data}

Physical activity. The mean physical activity level (IPAQ total score) was 5,763.5 MET-minutes per week $(S D=5,349.3$, range $=1,173-21,756) ; 37 \%$ of all participants were highly active and $63 \%$ were moderately active.

Depression symptoms. The mean BDI score was $5.4(S D=4.2$, range $=1-19)$. One person indicated mild, all other patients no or minimal severity of depressive symptoms.

Physical disability. The mean EDSS score was $3.5(S D=0.9)$.

Medication use (ADs). Eight patients reported the intake of AD medications such as selective-serotonin-reuptake inhibitors, selective noradrenalin-reuptake inhibitors, selective serotonin and noradrenalin-reuptake inhibitors, and tricyclic ADs. Intake of ADs was not associated with BDI scores, $t(25)=-2.029, p=.14$. Accordingly, intake of ADs was not introduced as confounder.

Mediation analysis with the IPAQ total score. The direct effect of disability on depressive symptoms was calculated with a multiple linear regression model and was significant $(p=.02)$. The first prerequisite to investigate the mediator effect of physical activity was therefore achieved according to the procedure adopted from Baron and Kenny (1986). However, the relationships to and from the mediator were not significant. More precisely, physical activity level was statistically related to neither disability nor depressive symptoms. Consequently, the mediation was very unlikely since the mediator was not related to the other variables. Nevertheless, to test the mediation hypothesis, the previously planned analyses were performed including the assessment of the indirect effect. 
Table I. Multiple Regression Analyses.

\begin{tabular}{|c|c|c|c|c|c|c|c|}
\hline Dimension & Variables & Coefficient & $\begin{array}{l}\text { Standard } \\
\text { error }\end{array}$ & $\begin{array}{c}\text { Coefficient } \\
\beta\end{array}$ & $t$ & $P$ & $\begin{array}{l}\text { Durbin- } \\
\text { Watson } \\
\text { coefficient }\end{array}$ \\
\hline \multicolumn{8}{|c|}{ Linear regression analysis to describe physical activity as dependent variable and physical disability as predictor. } \\
\hline \multirow{2}{*}{$\begin{array}{c}\text { Physical } \\
\text { activity } \\
\text { IPAQ }\end{array}$} & Intercept & $|433| .27$ & 3177.76 & - & 4.51 & .000 & - \\
\hline & Physical disability & -401.76 & 1031.07 & -.08 & -0.39 & .71 & \\
\hline \multicolumn{8}{|c|}{$\begin{array}{l}\text { Multiple linear regression analysis to describe symptoms of depression as dependent variable and physical disability anc } \\
\text { physical activity as predictor. }\end{array}$} \\
\hline \multirow{3}{*}{$\begin{array}{l}\text { Symptoms of } \\
\text { depression }\end{array}$} & Intercept & 3.75 & 3.581 & - & 2.969 & .046 & 1.907 \\
\hline & Physical disability & 2.21 & $0.84 I$ & .620 & 2.629 & .016 & \\
\hline & Physical activity & 0.09 & 0.003 & -.225 & -1.02 & .320 & \\
\hline
\end{tabular}

IPAQ = International Physical Activity Questionnaire.

First, the multiple regression analyses (see Table 1) following the approach of Baron and Kenny (1986) did not indicate a mediation. The inclusion of the physical activity level only minimally changed the direct effect of physical disability on depressive symptoms from $p=.01$ to $p=.02$. Second, the indirect effect, estimated with bootstrapping by using the PROCESS syntax, did not significantly differ from $0(0.07,95 \%$ CI $[-0.21,1.05])$. Hence, the indirect effect for the IPAQ total score, assessed with two different statistical methods, was not statistically significant. However, we also note that the beta weight between physical activity and symptoms of depression was negative, or simply put: higher physical activity levels were associated with fewer symptoms of depression.

\section{Discussion}

Key findings of the present study were that, among a sample of adult patients with diagnosed MS, higher disability scores and more depressive symptoms were associated, while self-reported levels of physical activity (total score) were statistically unrelated to degree of disability. However, while the regression weights (betas) were not statistically significant, we observed that higher levels of physical activity were associated with fewer symptoms of depression. Therefore, the present results add to the current literature in that we showed a direct association between disability and symptoms of depression, while, descriptively, increased physical activity was associated with lower scores for symptoms of depression.

With regard to our first hypothesis that higher disability scores would be associated with increased symptoms of depression, our data did confirm this and are in accord with previous results. In past studies, such associations were 
reported among elderly people (Cole \& Dendukuri, 2003; Cronin-Stubbs et al., 2000; Kennedy et al., 1990; Strawbridge et al., 2002; Turner \& Noh, 1988) and among patients with MS (Chwastiak et al., 2002; Kurtzke, 1983; Mcivor et al., 1984; Millefiorini et al., 1992; Mohr et al., 1997). However, the present results expand upon existing research in that we were also able to show such associations among a smaller sample of patients with MS who had taken antidepressant medication, and we showed that this association occurred irrespective of such possible confounders as age and gender.

With regard to our second hypothesis that higher physical activity scores (total score) would be associated with fewer symptoms of depression, again, our data showed this association trend in the expected direction, though the beta weight was not statistically significant $(p>.1)$, possibly because $p$-values are sensitive to sample sizes (Bosco, Aguinis, Singh, Field, \& Pierce, 2015), a limitation of our study.

With regard to our exploratory research question of whether self-reported physical activity would mediate the association between higher scores of disability and increased symptoms of depression, the answer was no. The present pattern of results did not confirm the assumption that physical activity has a mediating influence on the association between physical disability and symptoms of depression among patients with MS. Further, as reported in Figure 1, physical disability and physical activity were completely unrelated (beta $=-.0 .09$ ), suggesting other underlying links between physical disability and symptoms of depression in this population. The quality of our data does not allow a deeper understanding of any underlying physiological or psychological mechanisms, but we might speculate. First the current state of physical activity was unrelated to the current state of physical disability, because physical activity levels after disease onset are related to the amount of physical activity before disease onset (Motl et al., 2012). Future studies should assess physical activity levels before disease onset, in order to better understand this possible confound. Second, physical activity levels may vary as a function of lifestyle. Ekelund et al. (2016) showed that physical activity levels, inactivity, and a more healthy or unhealthy lifestyle were associated. Accordingly, future studies should assess more thoroughly such dimensions of life style as (a) leisure time activities, (b) low or moderate intake of substances such as alcohol and tobacco, (c) following nutritional guidelines such as eating fruits and vegetables in abundance, and keeping limiting the intake of fat and carbohydrates, and (d) keeping the wake-sleep-rhythm stable and in accord with day-night-time. Third, though highly unlikely, both the EDSS and the IPAQ may not adequately reflect physical disability and current physical activity levels.

Clinically, the present results replicate prior indications that patients with MS are at higher risk of depression, suggesting a need for thorough professional psychological support beyond that provided by neurologists. Future researchers should study why physical disability may lead to increased depressive symptoms 


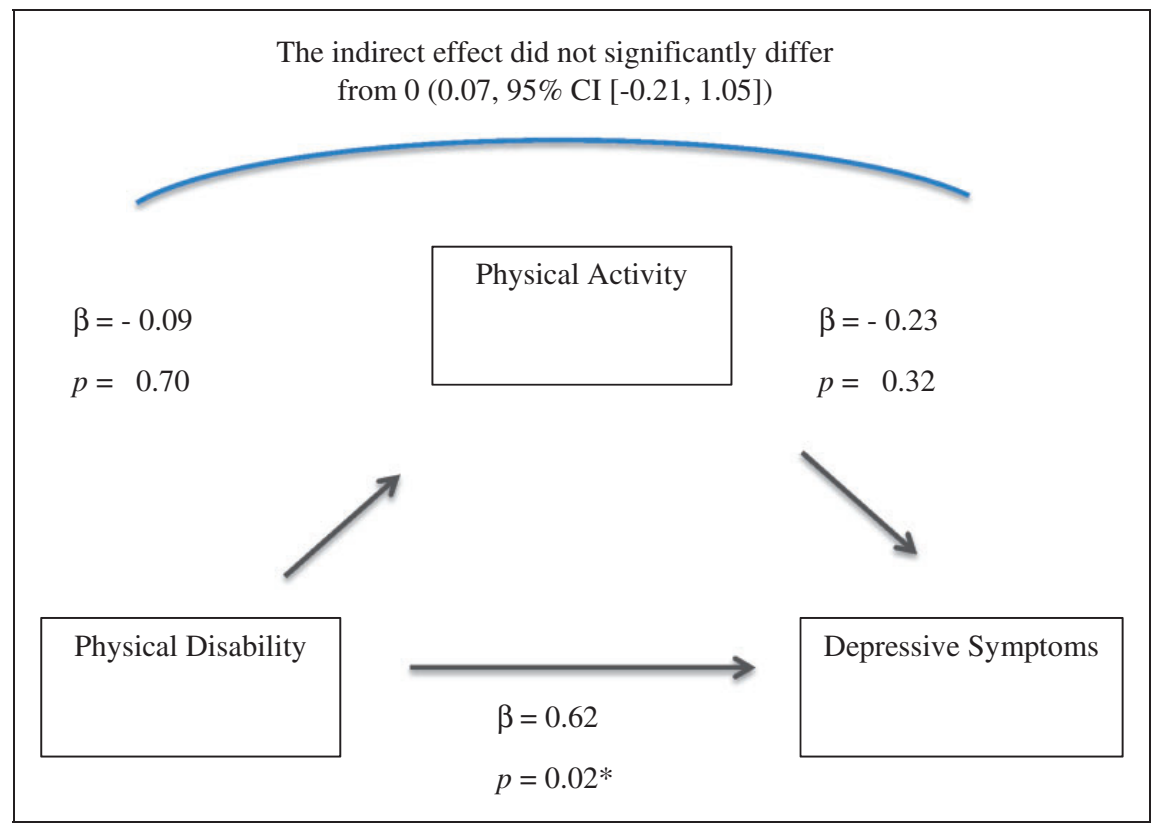

Figure I. The expected connectedness of the three factors, physical activity, physical disability, and depressive symptoms, using the IPAQ total score as the physical activity measure. Relationships between variables were tested with multiple regression analyses. The indirect effect was analyzed by bootstrapping.

in some, but not all, patients with MS. Simply and more specifically put: Which "psychological transmission belts" may link physical disability with greater or lesser symptoms of hopelessness, helplessness, and decreased interest in life? Perhaps psychotherapeutic interventions such as cognitive behavioral therapy, detached mindfulness, or stress management have the potential to disconnect physical disability from the dysfunctional cognitive-emotional processes that lead to symptoms of depression. Identifying such psychological factors may help explain why the degree of disability was not associated with degree of physical activity (see Figure 1) as would have been expected. Future research should also address how to motivate patients with MS to remain as physically active as possible, given the association between higher physical activity levels and fewer symptoms of depression in this study and in previous research (Kvam, Kleppe, Nordhus, \& Hovland, 2016; Schuch, Vancampfort, et al., 2016). Toward this end and based on prior literature (Gerber et al., 2016; Hallgren et al., 2016), we propose the following: (a) Exercising should be made as pleasant and enjoyable as possible, perhaps by choosing the right activities and intensities or creating an autonomy-supporting climate; and (b) any kind of physical 
activity (duration, frequency, intensity, type of activity) should be visualized, since visualizing progress provides powerful, easy, and efficient feedback that increases motivation and helps to compare one's own standards and performance over time, while comparisons with "artificial" or "virtual" standards such as health recommendations or examples from media, may decrease the selfpaced motivation. (Note that Lindegard, Jonsdottir, Borjesson, Lindwall, and Gerber, 2015, found changes in mental health among patients with stress-related exhaustion, who did not meet the minimum recommended three bouts of moderate to vigorous exercising per week.)

Our findings should be considered in light of several limitations suggesting a need for cautious interpretation. First, our sample size was small, and it precluded the detection of possible statistically significant findings, suggesting a need for future studies to use more participants. Second, we excluded patients with EDSS scores higher than 5, perhaps limiting the generalizability of these findings for patients with greater disability. Third, although our center treats all patients with MS, we did not include patients without sufficient German language skills. Fourth, physical activity was subjectively estimated through self-report which might have under or overestimated physical activity frequency, duration, and intensity (Fogelholm et al., 2006), in relation to more objective accelerometer data. Fifth, we relied on a subjective outcome data, while for instance, Bansi and coworkers (Bansi, Bloch, Gamper, \& Kesselring, 2013; Bansi, Bloch, Gamper, Riedel, \& Kesselring, 2013) reported favorable changes in inflammatory markers and fatigue after endurance and short-term intervention trainings. Future studies should utilize interventional designs and objective physiological measurements. Sixth, our patients with MS reported low symptoms of depression, interfering with a differentiated statistical approach to studying this variable. Seventh, we did not address such latent and potentially influential factors as fatigue, paresthesia, anxiety, sleep quality, or stress, all of which might have mediated these results and might be considered in future studies.

\section{Declaration of Conflicting Interests}

The author(s) declared no potential conflicts of interest with respect to the research, authorship, and/or publication of this article.

\section{Funding}

The author(s) received no financial support for the research, authorship, and/or publication of this article.

\section{References}

Archer, T., Josefsson, T., \& Lindwall, M. (2014). Effects of physical exercise on depressive symptoms and biomarkers in depression. CNS \& Neurological Disorders-Drug Targets, 13(10), 1640-1653. 
Bansi, J., Bloch, W., Gamper, U., \& Kesselring, J. (2013). Training in MS: Influence of two different endurance training protocols (aquatic versus overland) on cytokine and neurotrophin concentrations during three week randomized controlled trial. Multiple Sclerosis, 19(5), 613-621. doi:10.1177/1352458512458605

Bansi, J., Bloch, W., Gamper, U., Riedel, S., \& Kesselring, J. (2013). Endurance training in MS: Short-term immune responses and their relation to cardiorespiratory fitness, health-related quality of life, and fatigue. Journal of Neurology, 260(12), 2993-3001. doi:10.1007/s00415-013-7091-z

Baron, R. M., \& Kenny, D. A. (1986). The moderator mediator variable distinction in social psychological-research-conceptual, strategic, and statistical considerations. Journal of Personality and Social Psychology, 51(6), 1173-1182. doi:10.1037/00223514.51.6.1173

Beck, A. T., Ward, C. H., Mendelson, M., Mock, J., \& Erbaugh, J. (1961). An inventory for measuring depression. Archives of general psychiatry, 4, 561-571.

Benedict, R. H. B., Fishman, I., McClellan, M. M., Bakshi, R., \& Weinstock-Guttman, B. (2003). Validity of the beck depression inventory-fast screen in multiple sclerosis. Multiple Sclerosis, 9(4), 393-396. doi:10.1191/1352458503ms902oa

Bosco, F. A., Aguinis, H., Singh, K., Field, J. G., \& Pierce, C. A. (2015). Correlational effect size benchmarks. Journal of Applied Psychology, 100(2), 431-449. doi:10.1037/ a0038047

Brenner, P., \& Piehl, F. (2016). Fatigue and depression in multiple sclerosis: Pharmacological and non-pharmacological interventions. Acta Neurologica Scandinavica, 134, 47-54. doi:10.1111/ane.12648

Chiaravalloti, N. D., \& DeLuca, J. (2008). Cognitive impairment in multiple sclerosis. Lancet Neurology, 7(12), 1139-1151. doi:10.1016/S1474-4422(08)70259-X

Chwastiak, L., Ehde, D. M., Gibbons, L. E., Sullivan, M., Bowen, J. D., \& Kraft, G. H. (2002). Depressive symptoms and severity of illness in multiple sclerosis: Epidemiologic study of a large community sample. American Journal of Psychiatry, 159(11), 1862-1868. doi:10.1176/appi.ajp.159.11.1862

Cole, M. G., \& Dendukuri, N. (2003). Risk factors for depression among elderly community subjects: A systematic review and meta-analysis. American Journal of Psychiatry, 160(6), 1147-1156. doi:10.1176/appi.ajp.160.6.1147

Compston, A., \& Coles, A. (2008). Multiple sclerosis. Lancet, 372(9648), 1502-1517. doi:10.1016/s0140-6736(08)61620-7

Cooney, G. M., Dwan, K., Greig, C. A., Lawlor, D. A., Rimer, J., Waugh, F. R., Mead, G. E. (2013). Exercise for depression. Cochrane Database of Systematic Reviews, (9), CD004366. doi:10.1002/14651858.Cd004366.Pub6

Craig, C. L., Marshall, A. L., Sjöström, M., Bauman, A. E., Booth, M. L., Ainsworth, B. E., ... Oja, P. (2003). International physical activity questionnaire: 12-country reliability and validity. Medicine and Science in Sports and Exercise, 35, 1381-1395.

Cronin-Stubbs, D., de Leon, C. F. M., Beckett, L. A., Field, T. S., Glynn, R. J., \& Evans, D. A. (2000). Six-year effect of depressive symptoms on the course of physical disability in community-living older adults. Archives of Internal Medicine, 160(20), 3074-3080. doi:10.1001/archinte.160.20.3074

Dalgas, U., Stenager, E., Sloth, M., \& Stenager, E. (2015). The effect of exercise on depressive symptoms in multiple sclerosis based on a meta-analysis and critical 
review of the literature. European Journal of Neurology, 22(3), 443-437. doi:10.1111/ Ene. 12576

Devine, J. M., \& Zafonte, R. D. (2009). Physical exercise and cognitive recovery in acquired brain injury: A review of the literature. Physical Medicine and Rehabilitation, 1(6), 560-575. doi:10.1016/J.Pmrj.2009.03.015

Ekelund, U., Steene-Johannessen, J., Brown, W. J., Fagerland, M. W., Owen, N., Powell, K. E.,... Lee, I. M. (2016). Does physical activity attenuate, or even eliminate, the detrimental association of sitting time with mortality? A harmonised meta-analysis of data from more than 1 million men and women. Lancet, 388, 1302-1310. doi:10.1016/ s0140-6736(16)30370-1

Ensari, I., Motl, R. W., \& Pilutti, L. A. (2014). Exercise training improves depressive symptoms in people with multiple sclerosis: Results of a meta-analysis. Journal of Psychosomatic Research, 76(6), 465-471. doi:10.1016/J.Jpsychores.2014.03.014

Feinstein, A., Magalhaes, S., Richard, J. F., Audet, B., \& Moore, C. (2014). The link between multiple sclerosis and depression. Nature Reviews Neurology, 10(9), 507-517. doi:10.1038/Nrneurol.2014.139

Fogelholm, M., Malmberg, J., Suni, J., Santtila, M., Kyröläinen H., Mäntysaari, M.,... Oja, P. (2006). International physical activity questionnaire: Validity against fitness. Medicine and Science in Sports and Exercise, 38(4), 753-760.

Fiest, K. M., Walker, J. R., Bernstein, C. N., Graff, L. A., Zarychanski, R., Abou-Setta, A. M.,... Managing, C. T. D. B. (2016). Systematic review and meta-analysis of interventions for depression and anxiety in persons with multiple sclerosis. Multiple Sclerosis and Related Disorders, 5, 12-26. doi:10.1016/j.msard.2015.10.004

Gerber, M., Holsboer-Trachsler, E., Puhse, U., \& Brand, S. (2016). Exercise is medicine for patients with major depressive disorders: But only if the "pill" is taken! Neuropsychiatric Disease and Treatment, 12, 1977-1981. doi:10.2147/NDT.S1 10656

Giesser, B. S. (2015). Exercise in the management of persons with multiple sclerosis. Therapeutic Advances in Neurological Disorders, 8(3), 123-130. doi:10.1177/ 1756285615576663

Gold, S. M., \& Irwin, M. R. (2009). Depression and immunity: Inflammation and depressive symptoms in multiple sclerosis. Immunology and Allergy Clinics of North America, 29(2), 309-320. doi:10.1016/j.iac.2009.02.008

Gold, S. M., Kruger, S., Ziegler, K. J., Krieger, T., Schulz, K. H., Otte, C., \& Heesen, C. (2011). Endocrine and immune substrates of depressive symptoms and fatigue in multiple sclerosis patients with comorbid major depression. Journal of Neurology Neurosurgery and Psychiatry, 82(7), 814-818. doi:10.1136/jnnp.2010.230029

Goretti, B., Portaccio, E., Zipoli, V., Razzolini, L., \& Amato, M. P. (2010). Coping strategies, cognitive impairment, psychological variables and their relationship with quality of life in multiple sclerosis. Neurological Sciences, 31, 227-230. doi:10.1007/ S10072-010-0372-8

Guimaraes, J., \& Sa, M. J. (2012). Cognitive dysfunction in multiple sclerosis. Frontiers in Neurology, 3, 74. doi:10.3389/fneur.2012.00074

Haghighi, M., Khodakarami, S., Jahangard, L., Ahmadpanah, M., Bajoghli, H., Holsboer-Trachsler, E., \& Brand, S. (2014). In a randomized, double-blind clinical trial, adjuvant atorvastatin improved symptoms of depression and blood lipid values 
in patients suffering from severe major depressive disorder. Journal of Psychiatric Research, 58, 109-114. doi:10.1016/j.jpsychires.2014.07.018

Hallgren, M., Vancampfort, D., \& Stubbs, B. (2016). Exercise is medicine for depression: Even when the "pill" is small. Neuropsychiatric Disease and Treatment, 12, 2715-2721. doi:10.2147/NDT.S121782

Hayes, A. F. (2012). PROCESS: A versatile computational tool for observed variable mediation, moderation, and conditional process modeling. Retrieved from http://www. processmacro.org/download.html

Hayes, A. F. (2015). An index and test of linear moderated mediation. Multivariate Behavioral Research, 50, 1-22.

Howard, J., Trevick, S., \& Younger, D. S. (2016). Epidemiology of multiple sclerosis. Neurologic Clinics, 34(4), 919-939. doi:10.1016/j.ncl.2016.06.016

IPAQ Research Committee. (2005). Guidelines for Data Processing and Analysis of the International Physical Activity Questionnaire (IPAQ)-Short and long forms. Retrieved from https://sites.google.com/site/theipaq/scoring-protocol

Jones, K. H., Jones, P. A., Middleton, R. M., Ford, D. V., Tuite-Dalton, K., LockhartJones, H., ... Noble, J. G. (2014). Physical disability, anxiety and depression in people with MS: An internet-based survey via the UK MS Register. PLoS One, 9(8), e104604. doi:10.1371/journal.pone.0104604

Josefsson, T., Lindwall, M., \& Archer, T. (2014). Physical exercise intervention in depressive disorders: Meta-analysis and systematic review. Scandinavian Journal of Medicine \& Science in Sports, 24(2), 259-272. doi:10.1111/Sms.12050

Kennedy, G. J., Kelman, H. R., \& Thomas, C. (1990). The emergence of depressive symptoms in late life: The importance of declining health and increasing disability. Journal of Community Health, 15(2), 93-104.

Koch, M. W., Glazenborg, A., Uyttenboogaart, M., Mostert, J., \& De Keyser J. (2011). Pharmacologic treatment of depression in multiple sclerosis. The Cochrane Database of Systematic Reviews, 2011(2), CD007295. doi: 10.1002/14651858.CD007295.pub2

Krogh, J., Nordentoft, M., Sterne, J. A. C., \& Lawlor, D. A. (2011). The effect of exercise in clinically depressed adults: Systematic review and meta-analysis of randomized controlled trials. Journal of Clinical Psychiatry, 72(4), 529-538. doi:10.4088/Jcp.08r04913blu

Kuhner, C., Burger, C., Keller, F., \& Hautzinger, M. (2007). Reliability and validity of the revised Beck Depression Inventory (BDI-II). Results from German samples. Nervenarzt, 78(6), 651-656. doi:10.1007/s00115-006-2098-7

Kurtzke, J. F. (1983). Rating neurologic impairment in multiple-sclerosis-An expanded disability status scale (Edss). Neurology, 33(11), 1444-1452.

Kvam, S., Kleppe, C. L., Nordhus, I. H., \& Hovland, A. (2016). Exercise as a treatment for depression: A meta-analysis. Journal of Affective Disorders, 202, 67-86. doi:10.1016/j.jad.2016.03.063

Latimer-Cheung, A. E., Pilutti, L. A., Hicks, A. L., Martin Ginis, K. A., Fenuta, A. M., MacKibbon, K. A.,... Motl, R. W. (2013). Effects of exercise training on fitness, mobility, fatigue, and health-related quality of life among adults with multiple sclerosis: A systematic review to inform guideline development. Archives of Physical Medicine and Rehabilitation, 94(9), 1800-1828.e1803. doi:10.1016/j.apmr.2013.04.020

Lawlor, D. A., \& Hopker, S. W. (2001). The effectiveness of exercise as an intervention in the management of depression: Systematic review and meta-regression analysis of 
randomised controlled trials. British Medical Journal, 322(7289), 763-767. doi:10.1136/Bmj.322.7289.763

Lindegard, A., Jonsdottir, I. H., Borjesson, M., Lindwall, M., \& Gerber, M. (2015). Changes in mental health in compliers and non-compliers with physical activity recommendations in patients with stress-related exhaustion. BMC Psychiatry, 15, 272. doi:10.1186/s12888-015-0642-3

Lode, K., Bru, E., Klevan, G., Myhr, K. M., Nyland, H., \& Larsen, J. P. (2009). Depressive symptoms and coping in newly diagnosed patients with multiple sclerosis. Multiple Sclerosis, 15(5), 638-643. doi:10.1177/1352458509102313

Marck, C. H., Hadgkiss, E. J., Weiland, T. J., van der Meer, D. M., Pereira, N. G., \& Jelinek, G. A. (2014a). Physical activity and associated levels of disability and quality of life in people with multiple sclerosis: A large international survey. BMC Neurology, 14, 143. doi:10.1186/1471-2377-14-143

Marck, C. H., Hadgkiss, E. J., Weiland, T. J., Van der Meer, D. M., Pereira, N. G., \& Jelinek, G. A. (2014b). Physical activity and associated levels of disability and quality of life in people with multiple sclerosis: A large international survey. BMC Neurology, 14, p. 143. doi:10.1186/1471-2377-14-143

McCabe, M. P., McKern, S., \& McDonald, E. (2004). Coping and psychological adjustment among people with multiple sclerosis. Journal of Psychosomatic Research, 56(3), 355-361. doi:10.1016/S0022-3999(03)00132-6

McDonnell, M. N., Smith, A. E., \& Mackintosh, S. F. (2011). Aerobic exercise to improve cognitive function in adults with neurological disorders: A systematic review. Archives of Physical Medicine and Rehabilitation, 92(7), 1044-1052. doi:10.1016/J.Apmr.2011.01.021

Mcivor, G. P., Riklan, M., \& Reznikoff, M. (1984). Depression in multiple-sclerosis as a function of length and severity of illness, age, remissions, and perceived social support. Journal of Clinical Psychology, 40(4), 1028-1033.

Mead, G. E., Morley, W., Campbell, P., Greig, C. A., McMurdo, M., \& Lawlor, D. A. (2009). Exercise for depression. Cochrane Database of Systematic Reviews (3), CD004366. doi:10.1002/14651858.Cd004366.Pub4

Meyer-Moock, S., Feng, Y. S., Maeurer, M., Dippel, F. W., \& Kohlmann, T. (2014). Systematic literature review and validity evaluation of the Expanded Disability Status Scale (EDSS) and the Multiple Sclerosis Functional Composite (MSFC) in patients with multiple sclerosis. BMC Neurology, 14, 58. doi:10.1186/1471-2377-14-58

Millefiorini, E., Padovani, A., Pozzilli, C., Loriedo, C., Bastianello, S., Buttinelli, C.,... Fieschi, C. (1992). Depression in the early phase of Ms-Influence of functional disability, cognitive impairment and brain abnormalities. Acta Neurologica Scandinavica, 86(4), 354-358.

Mohr, D. C., Goodkin, D. E., Gatto, N., \& VanDerWende, J. (1997). Depression, coping and level of neurological impairment in multiple sclerosis. Multiple Sclerosis, 3(4), 254-258.

Montel, S., Spitz, E., \& Bungener, C. (2012). Coping strategies in multiple sclerosis patients with frontal cognitive disorders. European Neurology, 68(2), 84-88. doi: $10.1159 / 000337905$

Motl, R. W. (2010). Physical activity and irreversible disability in multiple sclerosis. Exercise and Sport Sciences Reviews, 38(4), 186-191. doi:10.1097/JES.0b013e3181f44fab 
Motl, R. W., Dlugonski, D., Pilutti, L., Sandroff, B., \& McAuley, E. (2012). Premorbid physical activity predicts disability progression in relapsing-remitting multiple sclerosis. Journal of the Neurological Sciences, 323(1-2), 123-127. doi:10.1016/ j.jns.2012.08.033

Motl, R. W., \& Pilutti, L. A. (2012). The benefits of exercise training in multiple sclerosis. Nature Reviews Neurology, 8(9), 487-497. doi:10.1038/Nrneurol.2012.136

Motl, R. W., \& Pilutti, L. A. (2016). Is physical exercise a multiple sclerosis disease modifying treatment?. Expert Review of Neurotherapeutics, 16(8), 951-960. doi:10.1080/14737175.2016.1193008

Patten, S. B., Beck, C. A., Williams, J. V. A., Barbui, C., \& Metz, L. M. (2003). Major depression in multiple sclerosis-A population-based perspective. Neurology, 61(11), 1524-1527.

Patten, S. B., Wang, J. L., Williams, J. V. A., Currie, S., Beck, C. A., Maxwell, C. J., ... el-Guebaly, N. (2006). Descriptive epidemiology of major depression in Canada. Canadian Journal of Psychiatry-Revue Canadienne De Psychiatrie, 51(2), 84-90.

Pilutti, L. A., Platta, M. E., Motl, R. W., \& Latimer-Cheung, A. E. (2014). The safety of exercise training in multiple sclerosis: A systematic review. Journal of the Neurological Sciences, 343(1-2), 3-7. doi:10.1016/j.jns.2014.05.016

Ploughman, M., Beaulieu, S., Harris, C., Hogan, S., Manning, O. J., WAlderdice, P.,... Godwin, M. (2014). The Canadian survey of health, lifestyle and ageing with multiple sclerosis: Methodology and initial results. BMJ Open, 4(7), e005718. doi:DOI 10.1136/bmjopen-2014-005718

Preacher, K. J., \& Hayes, A. F. (2008). Asymptotic and resampling strategies for assessing and comparing indirect effects in multiple mediator models. Behavior Research Methods, 40(3), 879-891.

Rabinowitz, A. R., \& Arnett, P. A. (2009). A longitudinal analysis of cognitive dysfunction, coping, and depression in multiple sclerosis. Neuropsychology, 23(5), 581-591. doi:10.1037/A0016064

Razazian, N., Yavari, Z., Farnia, V., Azizi, A., Kordavani, L., Bahmani, D. S., .. Brand, S. (2016). Exercising impacts on fatigue, depression, and paresthesia in female patients with multiple sclerosis. Medicine and Science in Sports and Exercise, 48(5), 796-803. doi:10.1249/mss.0000000000000834

Rethorst, C. D., Wipfli, B. M., \& Landers, D. M. (2009). The antidepressive effects of exercise a meta-analysis of randomized trials. Sports Medicine, 39(6), 491-511.

Rosenbaum, S., Tiedemann, A., Ward, P. B., Curtis, J., \& Sherrington, C. (2015). Physical activity interventions: An essential component in recovery from mental illness. British Journal of Sports Medicine, 49(24), 1544-1545. doi:10.1136/bjsports-2014094314

Sacco, R., Santangelo, G., Stamenova, S., Bisecco, A., Bonavita, S., Lavorgna, L., ... Gallo, A. (2016). Psychometric properties and validity of beck depression inventory II in multiple sclerosis. European Journal of Neurology, 23, 744-750. doi:10.1111/ene.12932

Sadeghi Bahmani, D., Gerber, M., Kalak, N., Lemola, S., Clough, P. J., Calabrese, P.,... Brand, S. (2016). Mental toughness, sleep disturbances, and physical activity in patients with multiple sclerosis compared to healthy adolescents and young 
adults. Neuropsychiatric Disease and Treatment, 12, 1571-1579. doi:10.2147/Ndt. S111208

Schuch, F. B., Morres, I. D., Ekkekakis, P., Rosenbaum, S., \& Stubbs, B. (2017). A critical review of exercise as a treatment for clinically depressed adults: Time to get pragmatic. Acta Neuropsychiatrica, 29, 65-71. doi:10.1017/neu.2016.21

Schuch, F. B., Vancampfort, D., Rosenbaum, S., Richards, J., Ward, P. B., Veronese, N., ... Stubbs, B. (2016). Exercise for depression in older adults: A meta-analysis of randomized controlled trials adjusting for publication bias. Revista Brasileira de Psiquiatria, 38(3), 247-254. doi:10.1590/1516-4446-2016-1915

Siegert, R. J., \& Abernethy, D. A. (2005). Depression in multiple sclerosis: A review. Journal of Neurology Neurosurgery and Psychiatry, 76(4), 469-475. doi:10.1136/ Jnnp.2004.054635

Snook, E. M., \& Motl, R. W. (2008). Physical activity behaviors in individuals with multiple sclerosis: Roles of overall and specific symptoms, and self-efficacy. Journal of Pain and Symptom Management, 36(1), 46-53. doi:10.1016/j. jpainsymman.2007.09.007

Stathopoulou, G., Powers, M. B., Berry, A. C., Smits, J. A. J., \& Otto, M. W. (2006). Exercise interventions for mental health: A quantitative and qualitative review. Clinical Psychology-Science and Practice, 13(2), 179-193. doi:10.1111/J.14682850.2006.00021.X

Strawbridge, W. J., Deleger, S., Roberts, R. E., \& Kaplan, G. A. (2002). Physical activity reduces the risk of subsequent depression for older adults. American Journal of Epidemiology, 156(4), 328-334. doi:10.1093/aje/kwf047

Stubbs, B., Rosenbaum, S., Vancampfort, D., Ward, P. B., \& Schuch, F. B. (2016). Exercise improves cardiorespiratory fitness in people with depression: A meta-analysis of randomized control trials. Journal of Affective Disorders, 190, 249-253. doi:10.1016/ j.jad.2015.10.010

Stuve, O., \& Oksenberg, J. (1993). Multiple sclerosis overview. In R. A. Pagon, M. P. Adam, H. H. Ardinger, S. E. Wallace, A. Amemiya, L. J. H. Bean, T. D. Bird, C. R. Dolan, C. T. Fong, R. J. H. Smith \& K. Stephens (Eds.), GeneReviews (R). Seattle, WA: University of Washington.

Turner, R. J., \& Noh, S. (1988). Physical-disability and depression-A longitudinal analysis. Journal of Health and Social Behavior, 29(1), 23-37. doi:10.2307/2137178

Vancampfort, D., Stubbs, B., Sienaert, P., Wyckaert, S., De Hert, M., Rosenbaum, S., \& Probst, M. (2015). What are the factors that influence physical activity participation in individuals with depression? A review of physical activity correlates from 59 studies. Psychiatria Danubina, 27(3), 210-224.

Waschbisch, A., Tallner, A., Pfeifer, K., \& Maurer, M. (2009). Multiple sclerosis and exercise-Effects of physical activity on the immune system. Nervenarzt, 80(6), 688-692. doi:10.1007/S00115-008-2639-3.

\section{Author Biographies}

Dena Sadeghi Bahmani has a MSc in clinical psychology from Esfahan University of Medical Sciences, Esfahan, Iran. Now, he is working as a doctoral student in Faculty of Psychology in the University of Basel, Basel, Switzerland. 
Pasquale Calabrese, $\mathrm{PhD}$, is working as a full-time professor in neurocognitive sciences, Faculty of Psychology, University of Basel, Basel, Switzerland.

Helene Merkt, MSc, is working as a research assistant in the Faculty of Psychology in University of Basel, Basel, Switzerland.

Yvonne Naegelin, MD, is the head physician in the Department of Neurology, University Hospital, Basel, Switzerland.

Markus Gerber, $\mathrm{PhD}$, is working as a full-time professor in the Department of Sport, Exercise and Health and the Head of the Division of Sport and Psychosocial Health in University of Basel, Basel, Switzerland.

Uwe Pühse, PhD, is working as a full-time professor, Department of Sport, Exercise and Health and Head of the Division of Sport Sciences in University of Basel, Basel, Switzerland.

Edith Holsboer-Trachsler, MD, is working as a full-time professor and as a head physician of the Center for Affective, Stress and Sleep Disorders (ZASS), Psychiatric Clinics (UPK), University of Basel, Basel, Switzerland.

Serge Brand, $\mathrm{PhD}$, is working as a research psychologist and adjunct professor at the Department of Sport, Exercise and Health, Division of Sport and Psychosocial Health, and at the Faculty of Psychology, University of Basel, Basel, Switzerland, and visiting professor at the Kermanshah University of Medical Sciences (KUMS), Kermanshah, Iran. 